\title{
Tariff Retaliation versus Financial Compensation in the Enforcement of International Trade Agreements*
}

\author{
Nuno Limão† and Kamal Saggi†
}

\begin{abstract}
We analyze whether financial compensation is preferable to the current system of dispute settlement in theWorld Trade Organization that permits member countries to impose retaliatory tariffs in response to trade violations committed by other members. We show that monetary fines are more efficient than tariffs in terms of granting compensation to injured parties when there are violations in equilibrium. However, fines suffer from an enforcement problem since they must be paid by the violating country. If fines must ultimately be supported by the threat of retaliatory tariffs, they fail to yield a more cooperative outcome than the current system. We also consider the use of bonds as a means of settling disputes. If bonds can be posted with a third party, they do not have to be supported by retaliatory tariffs and can improve the negotiating position of countries that are too small to threaten tariff retaliation. Keywords: Dispute Settlement, WTO, Tariffs, Monetary Fines, Bonds, Concessions, Reciprocity.
\end{abstract}

JEL Classifications: F23, F12

World Bank Policy Research Working Paper 3873, April 2006

The Policy Research Working Paper Series disseminates the findings of work in progress to encourage the exchange of ideas about development issues. An objective of the series is to get the findings out quickly, even if the presentations are less than fully polished. The papers carry the names of the authors and should be cited accordingly. The findings, interpretations, and conclusions expressed in this paper are entirely those of the authors. They do not necessarily represent the view of the World Bank, its Executive Directors, or the countries they represent. Policy Research Working Papers are available online at http://econ.worldbank.org.

* We thank Stephanie Aaronson, Kyle Bagwell, Chad Bown, Bernard Hoekman and Petros Mavroidis for useful discussions and comments. We gratefully acknowledge the financial support of the UK's Department for International Development.

†University of Maryland and CEPR. E-mail: Limao@econ.umd.edu. Part of this research was conducted while the author visited the World Bank Research Group in the summer of 2004. ¥Southern Methodist University. E-mail: ksaggi@smu.edu. 


\section{Introduction}

One of the major goals of the World Trade Organization (WTO) is to reduce policy barriers to international trade. Yet, its dispute settlement system allows members to raise tariffs in response to trade violations committed by other members. Although retaliation is permitted only as a last resort the fact that the WTO even permits tariff escalation appears to be a direct contradiction of the ideal of freer trade. This contradiction as well as the fact that many small countries cannot effectively retaliate via tariffs have lead to calls for alternative trade dispute remedies. ${ }^{1}$

There are at least two possible reasons why the WTO's Dispute Settlement Understanding (DSU) permits tariff retaliation. First, the threat of retaliation might encourage members to comply with WTO rules: in the absence of any fear of foreign retaliation, members would be tempted to raise their trade barriers whenever so urged by their import lobbies since domestic exporters would suffer no retaliation and thus would have little incentive to counter-lobby to keep the local market open. Second, tariff retaliation may allow an injured country to obtain partial compensation by either improving its terms of trade (which happens if it is large enough to affect world prices) or by benefiting those import competing sectors that are favored due to political economy considerations. Of course, even if tariff retaliation helps enforce cooperation and/or enable compensation in trade agreements, it may not necessarily be the optimal instrument for achieving these objectives. In principle, monetary fines payable by a country that violates WTO rules could have both a deterrent effect and a compensatory one while simultaneously avoiding the well-known inefficiencies of tariffs. Our goal in this paper is to evaluate whether the use of fines and bonds can improve upon the WTO's current dispute settlement system based on retaliatory tariffs.

The idea that trade disputes be settled via financial compensation has gained substantial

\footnotetext{
${ }^{1}$ See Hoekman and Kostecki (2001) for a good overview of the WTO's dispute settlement procedures. Lawrence (2003) notes that WTO rules are designed to preserve the existing balance of concessions (i.e. to maintain reciprocity). Ethier (2003) argues that the role of the WTO's dispute settlement procedure is "not to facilitate punishment: It is to constrain it."
} 
attention in recent years with several new proposals to reform the DSU in the Doha Round, which is still under way. ${ }^{2}$ Such proposals have tended to originate in countries that do not have sufficient market power to influence world prices and are therefore incapable of either inflicting significant harm on large countries or achieving compensation through tariff retaliation. Similar proposals were made in the early 1960s by Uruguay and Brazil who wanted less developed countries to be provided with financial compensation for GATT violations committed by developed countries. As Dam (1970) notes, such proposals are attractive for several reasons. First, the principle of financial liability to injured parties underlies domestic laws across the world and its use in international law seems natural. Second, tariff retaliation is often not in the interest of an injured party. For example, optimal tariffs for countries that are too small to influence world prices would be typically near zero. As a result, any tariff retaliation will only further reduce their welfare. ${ }^{3}$

Desirable as it may seem, the implementation of financial compensation faces important hurdles. We address what we think is the major hurdle: enforcing such a system. How does one ensure that the required fine, whatever it is ruled to be, is actually paid by a violating country? While an injured country can implement retaliatory tariffs without requiring any cooperation from a violating country, such is not the case for fines. Ultimately, a violating country has to agree to pay the fine and it will only do so when it is in its best interest since there exists no supra-national authority that can enforce the payment of the fine. ${ }^{4}$

\footnotetext{
${ }^{2}$ For example, in an article in the Financial Times of 24th June, 2004, Bronckers and Van Den Broek have argued strongly in favor of financial compensation as a means of settling trade disputes. See Bronckers and Van Den Broek (2005) for an in-depth discussion of the legal and economic arguments in favor of financial compensation.

${ }^{3}$ One alternative is for such countries to retaliate in other parts of the WTO agreement. In the recent bananas dispute involving the European Union (EU) and several banana exporters, Ecuador was authorized to do so and it threatened the EU that it would not respect the intellectual property provisions in the TRIPS for EU products unless the EU carried out the DSU ruling (WTO document WT/DS27/ARB/ECU, 2000). Limão (2005) provides a formal analysis of the enforcement effects of this type of linkage of cooperation across issues with international spillovers in the context of trade agreements. Although this is legally possible, Ecuador must no longer think this recourse is sufficiently satisfactory since it is one of the countries that recently proposed monetary fines to address trade disputes (WTO document TN/DS/W/9, 2002). A different proposal was put forward by Mexico who argued that injured countries be allowed to trade their retaliation rights, i.e. to "sell" them to countries that have sufficient market power to credibly threaten tariff retaliation. Bagwell, Mavroidis, and Staiger (2004a) analyze this proposal and formally show how a properly designed auction for retaliation rights would be efficiency improving.

${ }^{4}$ Another hurdle might be an informational one: determining the financial loss incurred by an exporter.
} 
This enforcement problem with financial compensation is clearly reflected in the current DSU - it allows for compensation but does not specify the form it must take. Article 22.2 of the DSU states that the compensation must be mutually agreed upon and if it is not, an injured country can apply for retaliation. The only case that we know of where a dispute resulted in monetary compensation was when the US was found guilty of non-payment of royalties by US firms to the EU. This shows that while financial compensation is possible under the DSU, it simply has not been agreed to in most trade disputes that have come before the WTO. ${ }^{5}$

An important objective of this paper is to analyze the effectiveness of alternative dispute remedies in maintaining relatively low trade barriers. We also analyze the effectiveness of the different systems from the perspective of compensating injured countries. In so doing, we argue that one needs to account not only for how a remedy is able to enforce cooperation but also how the remedy itself can be enforced. For fines to succeed in enforcing low tariffs and providing compensation, it is crucial that they be backed by a supporting instrument that is not controlled by a violating country. Retaliatory tariffs are the obvious choice for such a supporting instrument. However, we show that a system where retaliatory tariffs are used to support the payment of fines yields no more cooperation than one that uses tariffs alone to retaliate against violations.

The equivalence of fines and tariff retaliation in terms of enforcement suggests that both mechanisms yield the same payoffs. However, we show that this is only true if there are no deviations from cooperation in equilibrium. When such deviations occur, and they clearly do in practice, we show that fines supported by tariffs have an advantage over tariff retaliation as a primary remedy. Namely, the payoff to an injured country is higher under fines even though the cost of the penalty for a violating country is unchanged. Thus we

However, a similar issue occurs under the current tariff retaliation system. For more recent discussions by legal scholars on improvements of the WTO's DSU and use of monetary compensation see Shaffer (2003) and Hudec (2002).

${ }^{5}$ However, recently monetary fines have been introduced by the US in its preferential trade agreements with Singapore, Chile, the central American countries, and Australia. More specifically, in these agreements, monetary fines are typically a preferred form of compensation when there is a violation related to the trade or intellectual property right provisions. 
show that switching to fines generates a Pareto improvement in the presence of shocks that result in disputes along the equilibrium path. The underlying motive for this result is that tariffs are an inefficient form of compensation because the welfare gain they generate for an injured country (if it has market power) is always less than the welfare cost imposed on the country that committed the original violation. ${ }^{6}$

Given that tariff retaliation is usually not a credible threat for small countries, it is important to know whether such countries can benefit from enforcement mechanisms that do not rely on tariff retaliation. To this end, we ask whether international cooperation can be sustained by a system where each country posts a bond of a given amount prior to trading, with the understanding that its bond will be used to pay a fine in case it commits a trade violation. We find that bonds can only improve enforcement relative to a system based on retaliatory tariffs if they are held by a third party. Otherwise, i.e., if bonds are simply exchanged by two countries, a deviating country would have no incentive to return the other country's bond and ultimately the threat of tariff retaliation would once again be required. By contrast, if bonds are deposited in an escrow fund (i.e. with a third party), tariff retaliation is no longer necessary since the bond posted by the violating country can be used to compensate the injured country. Such an escrow scheme was in fact proposed by Chile in its bilateral trade agreement with the US. ${ }^{7}$

Finally, we show that bonds can help solve a collective action problem by small countries and enable them to obtain tariff concessions from large countries. This point needs elaboration. One problem facing small countries in reciprocal trade negotiations is that their individually optimal tariffs are low (even though they may be able to jointly exert enough market power to hurt large countries). Therefore, if a large country violates its com-

\footnotetext{
${ }^{6}$ In a different context, Hoekman and Saggi (2006) argue that since most developing countries lack the institutional capacity for fighting foreign export cartels via antitrust enforcement, developed countries ought to ban such cartels in return for tariff concessions or some monetary compensation. Cartelization creates an inefficiency much like the use of a tariff by a large country in that the loss suffered by the injured party exceeds the gain of the other party. They show that if tariff retaliation is a credible option for an importing low income country, the transfer it has to pay to its high income trade partner in order to secure a ban on export cartels is lower.

7 "Chile Looks for Monetary Sanctions as Enforcement Mechanism", INSIDE U.S. TRADE 13, $11 / 11 / 2002$.
} 
mitments and increases its tariff on a product exported by several small countries, none of them has an individual incentive to punish the large country via tariff retaliation. In fact, each small country prefers that some other country undertake the retaliation. Anticipating this free riding, a large country has no motive to offer tariff reductions in products primarily exported by small countries. Bonds solve the free riding problem since small countries no longer need to retaliate via tariffs. This allows small countries to credibly coordinate their threats against a large country and thus obtain tariff concessions from it.

The structure of the paper is as follows. In section 2 we introduce the model and derive the Nash and cooperative tariffs in the absence of enforcement problems. In section 3 we introduce the alternative enforcement mechanisms and contrast their outcomes in terms of the liberalization they can enforce. In section 4 we discuss the implications of bonds for

small countries. We also show the ex-post efficiency of fines relative to tariff retaliation as a form of compensation when trade disputes occur in equilibrium. In section 5 we summarize the results and discuss possible extensions.

\section{Model}

Given that the issue of alternative enforcement mechanisms is not yet well understood we start with the simpler case of two symmetric countries (home and foreign). In section 4 we consider the case where countries are asymmetric in size. Each country produces two homogeneous goods, $i=x, y$, where $x$ denotes home's import. Under trade, domestic import prices are given by $p=p^{w}+\tau$ where $p^{w}$ is the "world" price and $\tau$ is a specific import tariff. Home's excess demand is then $M_{i} \equiv D_{i}\left(p_{i}\right)-S_{i}\left(p_{i}\right)$ where $D_{i}$ measures demand for good $i$ and $S_{i}$ its supply. Denoting foreign variables with an asterisk $\left(^{*}\right)$, the world price $p^{w}$ is determined by the usual market clearing condition and is therefore a function of the policy variables. For the home country's import good, the market clearing condition is given by

$$
M_{x}\left(p_{x}^{w}, \tau\right)+M_{x}^{*}\left(p_{x}^{w}\right)=0
$$


A similar condition applies to foreign's import good, $y$. We assume that no export policies are used so that trade policy is simply described by the level of the import tariff in each country, $\tau$ and $\tau^{*}$. Moreover, we assume that countries have market power in trade so that their optimal tariffs are positive. It is then simple to verify that, in this setup, tariffs lower world prices, $p_{i}^{w}$, and raise the domestic ones.

We focus directly on a reduced form objective function for the government that may allow extra weight (measured by $\lambda_{i} \geq 1$ ) to be placed on producer surplus relative to consumer surplus and tax revenue:

$$
W_{i} \equiv \int_{p_{i}}^{\infty} D_{i}\left(p_{i}\right) d p_{i}+\lambda_{i} \int_{0}^{p_{i}} S_{i}\left(p_{i}\right) d p_{i}+\tau_{i} M_{i}
$$

When the government's objective in choosing trade policy is to simply maximize $W \equiv$ $\Sigma_{i} W_{i}$ this represents the reduced form of a political contributions model such as GrossmanHelpman (1994). ${ }^{8}$

The Nash tariff is obtained by maximizing (2) while taking the other country's tariff as given. Since we do not model export policies the good subscript, $i$, can be dropped. Let

$$
\tau^{N} \equiv \underset{\tau}{\arg \max } W
$$

which implies that the Nash tariff in ad-valorem terms, $\tau^{N} / p^{w}$, is given by:

$$
\frac{\tau^{N}}{p^{w}}=\frac{1}{\varepsilon}+(\lambda-1) \frac{S / M}{\xi}
$$

The first term on the right hand side of the equation above, $1 / \varepsilon$, is the inverse of the foreign export supply elasticity and it reflects the terms-of-trade motive for the use of tariffs. The second term reflects a political economy motive that is increasing in the extra weight placed on producers $(\lambda)$ and decreasing in home's import demand elasticity $(\xi) .{ }^{9}$ Given symmetry,

\footnotetext{
${ }^{8}$ In Grossman-Helpman (1994) the government's objective is $W^{G H}=a \bar{W}+c$, where $\bar{W}$ is social welfare, $c$ is political contributions and $a$ is the marginal rate of substitution between the two. In $W_{i}$ the term $\lambda-1$ can be directly interpreted as the inverse of $a$ when factor ownership is extremely concentrated.

${ }^{9}$ See the appendix for the derivation and exact definitions.
} 
the foreign country's import tariff is also the same, i.e. $\tau_{x}^{N}=\tau_{y}^{N *}$.

At the other extreme, if cooperation was not subject to any enforcement problems, countries would choose tariffs that maximize their joint objective $W+W^{*}$. This is equivalent to maximizing the objective of either one once we employ symmetry and note that $\tau=\tau^{*}$. Thus we obtain

$$
\tau^{g} \equiv \arg _{\tau^{c}} \max W_{x}\left(\tau^{c}\right)+W_{y}\left(\tau_{y}^{*}=\tau^{c}\right)
$$

which implies that the globally optimal ad-valorem tariff $\tau^{g} / p^{w}$ is given by

$$
\frac{\tau^{g}}{p^{w}}=(\lambda-1) \frac{S / M}{\xi}
$$

It is simple to see that the globally optimal cooperative tariff is lower than the noncooperative tariff (i.e. $\tau^{g} / p^{w}<\tau^{N} / p^{w}$ ). The difference between the Nash and globally cooperative policies confirms that market power in trade leads to international externalities that can potentially be resolved by trade agreements (as argued in Bagwell and Staiger [1999]). Moreover, it points out that even in the presence of an international agreement, countries may choose to have positive tariffs due to internal political economy distortions. Since the globally optimum tariff is below the level that is optimal for each individual country, each country has an incentive to deviate from it and would do so if it faced no punishment. We now address how countries can enforce cooperation.

\section{Enforcement of trade agreements}

The absence of a supra-national authority to punish violators implies that international agreements must be self-enforcing. Cooperative self-enforcing agreements are well characterized by certain repeated games. ${ }^{10}$ We begin with the standard approach in the literature of using the threat of tariff retaliation to enforce cooperation and then contrast its outcome with alternative enforcement mechanisms.

\footnotetext{
${ }^{10}$ See Dixit (1987) and Bagwell and Staiger (1990) for example.
} 


\subsection{Supporting cooperation via tariff retaliation}

Consider an indefinitely repeated game where the stage game delivers the Nash tariff described in the previous section. Assume that governments observe each other's actions at the end of each period. The strategy employed by countries is to start by cooperating until one deviates by raising its tariff. Any deviation is followed by a punishment phase of $n$ periods after which cooperation is resumed. The motive for modelling temporary punishments is that they are clearly more realistic than infinite Nash reversion. Although the latter is a possibility, we view it as the ultimate punishment corresponding to an unravelling of the GATT/WTO system that results from member countries not following its rules. The more common occurrence are trade disputes that are met with temporary punishments, which is more similar to what we now model. ${ }^{11}$

To find the lowest cooperative tariff that is renegotiation proof we must first define the payoffs to each government under the alternative situations that can arise. In the absence of cooperation, the payoff to each country equals the government's objective evaluated at $\tau^{N}$ :

$$
W^{N} \equiv W_{x}\left(\tau^{N}\right)+W_{y}\left(\tau^{* N}=\tau^{N}\right)
$$

Similarly, when countries cooperate, i.e. set their tariffs at $\tau^{c}$ (that is determined below), the payoff to each is given by:

$$
W^{C} \equiv W_{x}\left(\tau^{c}\right)+W_{y}\left(\tau^{* c}=\tau^{c}\right)
$$

If a country deviates, it does so by imposing its optimal Nash tariff $\tau^{N}$ on its trading partner who, in that period, still utilizes the cooperative tariff, $\tau^{c}$. The payoff to a country in the period it deviates is therefore given by

$$
W^{D} \equiv W_{x}\left(\tau^{N}\right)+W_{y}\left(\tau^{*}=\tau^{c}\right)
$$

\footnotetext{
${ }^{11}$ Here we focus on a case where there are no deviations occur in equilibrium. In section 4 we examine the compensation aspect of different remedies when shocks cause a deviation to occur.
} 
Since we allow for renegotiation after a deviation we must model the punishment phase before cooperation is resumed. We assume that countries agree that a deviation will be followed by $n$ periods of punishment where the country that deviated faces $\tau^{*}=\tau^{N}$ and must show its willingness to restart cooperation by setting its own tariff at the cooperative level $\tau^{c}<\tau^{N}$. The per-period payoff for the deviating country during the punishment phase is therefore

$$
W^{P} \equiv W_{x}\left(\tau^{c}\right)+W_{y}\left(\tau^{*}=\tau^{N}\right)
$$

Given these payoffs, the incentive compatibility (IC) constraint needed to sustain cooperation is

$$
W^{D}+V^{\tau} \leq \frac{W^{C}}{1-\delta}
$$

That is, the sum of the payoff of a deviation, $W^{D}$, and the continuation payoff, $V^{\tau}$, should not exceed the discounted payoff of cooperation. We define $\delta=\bar{\delta} \rho<1$ where $\bar{\delta}$ reflects a proper discount factor, $\rho$ is the probability that the game continues for one more period, and $V^{\tau}$ is the continuation payoff under tariff retaliation:

$$
V^{\tau} \equiv \Sigma_{t=1}^{n} \delta^{t} W^{P}+\Sigma_{t=n+1}^{\infty} \delta^{t} W^{C}
$$

Since $W^{P}<W^{N}$ the punishment phase is subgame perfect only if it is not profitable for the country that is being punished to simply abandon the agreement and revert to Nash forever. So we require that $V^{\tau}$ exceed the Nash payoff in order to be weakly renegotiation proof (WRP): ${ }^{12}$

$$
V^{\tau} \geq \frac{\delta}{1-\delta} W^{N}
$$

Because $W^{C}>W^{P}$ the longer the punishment phase, the lower is $V^{\tau}$. Therefore the maximum punishment that is WRP is found by increasing $n$ to lower the continuation

\footnotetext{
${ }^{12}$ Farrell and Maskin (1989) and Van Damme (1989) show that using the following punishment as part of the strategy is WRP: the party that deviates accepts to be punished and during that period it plays cooperatively. In this case clearly $W^{P}<W^{N}$. The WRP concept requires the strategy not to be Pareto dominated (i.e. $W^{* P}>W^{* C}$ ) so that cooperation does not Pareto dominate the punishment phase for the injured party. When this is the case, the foreign country is better off when home is punished than under cooperation but home is worse off.
} 
payoff until it is equal to the RHS of (12). We define this value as $n^{\text {max }}$, which is implicitly given by

$$
V^{\tau \min } \equiv \delta \frac{1-\delta^{n_{\max }}}{1-\delta} W^{P}+\frac{\delta^{n^{\max }+1}}{1-\delta} W^{C}=\frac{\delta}{1-\delta} W^{N}
$$

To confirm that the lowest cooperative tariff that is WRP is identical to the one under infinite Nash reversion we can replace (13) in (10) to obtain

$$
W^{D}+\frac{\delta}{1-\delta} W^{N} \leq \frac{1}{1-\delta} W^{C}
$$

The lowest self-enforcing tariff under infinite Nash reversion or WRP is implicitly defined when (14) holds with equality. This serves as a convenient benchmark against which alternative enforcement mechanisms can be compared. Since we are interested in enforcement problems we assume that the global optimum tariff is not self-enforcing under tariff retaliation, i.e. that $\delta$ in (14) is too low to sustain $\tau^{g}$.

\subsection{Fines and tariff retaliation}

We now consider the effect of switching from tariff retaliation to a monetary fine to punish deviations from a trade agreement. One key difference between these options is that the fine must be voluntarily paid by the deviating country whereas retaliatory tariffs are imposed by the other country. This means that if the country that deviates decides not to pay the fine, the only thing the other country can ultimately do is to revert to non-cooperation in tariffs, which in our model is equivalent to leaving the agreement altogether. Given this, the most cooperative tariff that can be achieved for a given fine of value $f$ is determined as follows.

First, after a deviation, a country must face a punishment payoff equal to the cooperative payoff net of the monetary fine: $W^{P}=W^{C}-f$. We assume that this fine is paid in the form of a numeraire good that is valued according to a quasilinear utility function. ${ }^{13}$ It is

\footnotetext{
${ }^{13}$ We can model this explicitly by assuming, for example, that each period countries get an endowment of some value $\beta>f$ that can be consumed or partially used for the fine. Alternatively, the numeraire can be produced using labor only in a constant returns production process. Since in either case the surplus
} 
reasonable to suppose that if the fine is paid, the transfer occurs in a single period. Thus we set $n=1$ without loss of generality since we can always alter the value of the fine, $f$, to mimic the effects of changes in $n$. The incentive constraint is then similar to the one we had previously, with the possible exception of the continuation payoff that is now $V^{f}$ :

$$
W^{D}+V^{f} \leq \frac{W^{C}}{1-\delta}
$$

The continuation payoff $V^{f}$ is now the cost of the fine, $-\delta f$, plus the stream of cooperative payoffs

$$
V^{f} \equiv-\delta f+\frac{\delta}{1-\delta} W^{C}
$$

If we ignore the renegotiation proofness constraint, there exists a sufficiently large $f$ that delivers the global optimum, $\tau^{g}$. However, we must ensure that the punishment payoff is WRP. Also, since in the absence of tariff retaliation a deviating country has no incentive to pay the fine, there ultimately must be a punishment for not doing so. In the context of our model, the only punishment that the other country can impose is to increase its tariff. Therefore the WRP constraint is defined with respect to the payoff under infinite Nash reversion and it requires that

$$
V^{f} \geq W^{N} \delta /(1-\delta)
$$

Thus WRP requires the maximum fine, $f^{\max }$, and resulting minimum payoff that the deviating country can be held to, $V^{f \min }$, to be

$$
V^{f \min } \equiv-\delta f^{\max }+\frac{\delta}{1-\delta} W^{C}=\frac{\delta}{1-\delta} W^{N}
$$

which implies that the maximum fine that is WRP is the present discounted value of from the numeraire good before fines is identical under cooperation and/or deviation, we need not include it explicitly in the payoff expressions since such inclusion does not alter the incentive constraints (and thus tariffs). 
cooperation in the trade agreement, i.e.

$$
f^{\max }=\left(W^{C}-W^{N}\right) /(1-\delta)
$$

By substituting $V^{f}=V^{f \min }$ in (15) we can obtain the lowest cooperative tariff that is WRP when fines are used and enforced by the threat of abandoning the agreement altogether. This gives

$$
W^{D}+\frac{\delta}{1-\delta} W^{N} \leq \frac{W^{C}}{1-\delta}
$$

This constraint is identical to the one under tariff retaliation in (14). We summarize this result in the following proposition.

Proposition 1 (Enforcement equivalence of tariffs and fines):

In a trade agreement between two symmetric countries, the most cooperative tariff that can be enforced by tariff retaliation is equal to the tariff that can be enforced with WRP fines.

The basic intuition behind this result becomes clear after we note two points. First, since the fine must be paid by the violating country it must find it in its best interest to do so. Therefore, the fine itself needs to be enforced. In the absence of additional instruments this enforcement must rely on the threat of infinite tariff retaliation, i.e. the breakdown of the trade agreement. Second, the maximum punishment that is WRP is the payoff that the deviating country would get if it abandoned the agreement. This is true of the value of the fine paid and the cost imposed by temporary tariff retaliation. Thus both alternatives yield the same cooperative tariff.

There is one important corollary of proposition 1. Since the most cooperative tariff is identical under these two mechanisms, the payoffs are also exactly the same. This is because thus far we have not introduced any deviations in equilibrium and, along the equilibrium path, countries always obtain the cooperative payoff $W^{C}$ (that depends only on the level of the cooperative tariff). In section 4.2 we show that if deviations do occur along the equilibrium path, the payoffs under the two mechanisms are different. Before doing so, we 
analyze whether an alternative enforcement mechanism can improve cooperation relative to the ones analyzed above.

\subsection{Exchanging bonds}

Suppose that at the beginning of every period each country posts a bond of value $b$ (measured in an untaxed numeraire good) that is used to pay a fine in case it commits a violation. Assume also that countries observe this and cooperate only if such a bond is posted by both of them. Naturally, once bonds are posted, countries are free to decide whether to cooperate on tariffs or not. If either country does not post a bond, both play Nash in tariffs forever (we later discuss the case where the punishment phase is finite).

As a baseline, suppose that there is no third party that holds the bonds so that governments must post them with each other (either a third party is not available or using it is too expensive due to transaction costs and/or non-verifiability). If at the end of a period both countries have cooperated then they "return" their bonds to each other, otherwise the country that deviated loses its bond.

Under infinite Nash reversion, if a country deviates in tariffs it will be optimal for it not to return the other country's bond. In this case, the equilibrium tariff remains unchanged relative to the case of no bonds. To see this, note that the incentive constraint is given by:

$$
\left(W^{D}+b^{*}-b\right)+\frac{\delta}{1-\delta} W^{N} \leq \frac{W^{C}}{1-\delta}
$$

where the payoff under Nash reversion is the same as before since under no cooperation both countries simply set their tariffs at $\tau^{N}$ and bonds are irrelevant. The functional form of the cooperation payoff is also unchanged because we assume that if countries cooperate they receive their bond and consume it at the end of the period (and we assume no discounting within the period). The key difference is the deviation payoff, which is now given by the original value, $W^{D}$, net of the value of the bond that is lost, $-b$ and the one not returned, $b^{*}$. However, if, as we expect due to symmetry and stationarity, the optimal bond is the same for both countries (i.e. $b^{*}=b$ ), the constraint in (21) is identical to the one in (14) 
and thus the resulting cooperative tariff is equal to that under infinite Nash reversion.

Now consider the case where the punishment phase is finite. Countries start cooperating by initially posting a bond $b$ with each other. If a country deviates from the cooperative tariff, it loses its bond. For cooperation to be resumed, the deviating country must return the present discounted value of the bond of the injured country, $b^{*} / \delta$. If it does so in the period after which the deviation occurs, tariffs return to the cooperative level. The incentive constraint for cooperation can be written as:

$$
W^{D}+b^{*}-b+V^{b} \leq \frac{W^{C}}{1-\delta}
$$

We can again write the minimum continuation payoff that is WRP:

$$
V^{b \min } \equiv-\frac{\delta b^{* \max }}{\delta}+\frac{\delta W^{C}}{1-\delta}=\frac{\delta}{1-\delta} W^{N}
$$

which implies a maximum bond of

$$
b^{* \max }=b^{\max }=\delta \frac{W^{C}-W^{N}}{1-\delta}
$$

Replacing this in (22) we obtain an IC for the lowest cooperative tariff under bonds that is exactly the same as in (21), which we already noted yields the same tariff as infinite Nash reversion.

\subsection{Bonds with third party enforcement}

If a third party holds the bonds, a country that cooperates always receives its bond at the end of the period (in addition to receiving the bond of the deviating country). Therefore the gain from deviation is now $W^{D}-b$. Moreover, since the country that deviates has no control over the bond of the other country, cooperation can be resumed in the following 
period. Therefore the IC is now

$$
W^{D}-b+\frac{\delta}{1-\delta} W^{C} \leq \frac{W^{C}}{1-\delta}
$$

where, since the full punishment of deviation is incurred in the deviation period, the continuation payoff is simply $\frac{\delta}{1-\delta} W^{C}$. This implies that the WRP constraint is always satisfied and that a bond of value

$$
b=\frac{\delta}{1-\delta}\left(W^{C}-W^{N}\right)
$$

is feasible. This bond enforces the same cooperative tariffs as bonds without a third party (as well as Nash reversion etc.). However, a larger bond can also be used since the WRP constraint does not bind and such a bond can enforce a lower tariff. Therefore the use of bonds held by third parties can improve on the level of cooperation achieved by the other enforcement mechanisms and it requires no threat of tariffs.

Consider now the case when fines are used for temporary punishment and a bond is posted but forfeited only if a fine is not paid. After a tariff deviation, the bond is held and its present discounted value is only released when the fine is paid. So the IC now becomes

$$
\left(W^{D}-b\right)+V^{\tau b} \leq \frac{W^{C}}{1-\delta}
$$

The maximum fine and associated minimum $V^{\tau b}$ that ensures the punishment is WRP, requires the following. The payoff from paying the fine and receiving the bond held at the time of deviation and continuing tariff cooperation must be at least as large as the payoff from not paying the fine, forfeiting the bond and continuing tariff cooperation. Thus

$$
V^{\tau b \min } \equiv \delta b / \delta-\delta f^{\max }+\frac{\delta}{1-\delta} W^{C}=\frac{\delta}{1-\delta} W^{C}
$$

Therefore the maximum fine that is WRP is $f^{\max }=b / \delta$. Substituting in (26) we obtain

$$
W^{D}-b+\frac{\delta}{1-\delta} W^{C} \leq \frac{W^{C}}{1-\delta}
$$


This condition is exactly the same as the one we obtained in the absence of fines, i.e. (24). Again, we could choose the bond value $b=\frac{\delta}{1-\delta}\left(W^{C}-W^{N}\right)$ (or higher) to obtain a cooperative tariff that is at least as low as that can be supported by fines under infinite tariff reversion. The key difference relative to the case of no bonds is that now the same cooperative tariff (or lower) can be obtained without ever requiring tariff retaliation or its threat. $^{14}$

We summarize the results on the enforcement properties of bonds versus tariffs in the following proposition.

Proposition 2 (Enforcement under tariffs versus bonds):

In a trade agreement between two symmetric countries, the most cooperative tariff that can be enforced by tariff retaliation is

(a) equal to the tariff enforced by WRP bonds exchanged between them and

(b) higher than the tariff enforced by WRP bonds posted with a third party.

This proposition reinforces the point that financial compensation can only improve on tariff retaliation if the compensation itself is enforced by something other than tariffs. The alternative presented in this proposition is to post the bonds with a third party that has the ability to ensure that compensation is paid by the party that commits a violation. ${ }^{15}$

\footnotetext{
${ }^{14}$ In terms of enforcement levels, there is no obvious advantage in this simple model to using fines supported by bonds as opposed to simply using bonds in this model since the lowest cooperative tariff is identical under the two alternatives.

${ }^{15}$ If bonds cannot be used to support fines, perhaps fines could be auctioned by smaller countries to those that have sufficient market power to credibly threaten tariff retaliation. Bagwell, Mavroidis and Staiger (2004a) show that if a violating country can also bid for the right to retaliate (in order to retire it), then it ends up winning the auction and the final result is effectively a cash payment to the injured party that does not have the capacity to retaliate. Furthermore, they show that an auction in which the violating party also participates is in general superior to one in which it does not. Their results imply that if the right to retaliate could be auctioned, compliance with WTO rules is likely to improve since even small countries could then effectively threaten retaliation. It is easy to see that their argument is even stronger in our context: by its very nature, the right to collect a fine ought to be more tradable (and hence more valuable to third parties) than the right to retaliate via tariffs. After all trading retaliatory measures requires the participation of at least one country large enough to credibly threaten retaliation. This is clearly not necessary for fines backed by bonds.
} 


\section{Extensions}

\subsection{Asymmetries in country size}

We now discuss some of the implications of our analysis for the case where countries are asymmetric in size. This is important because small countries may lack the ability to use tariff retaliation and apparently stand the most to gain from a switch to fines. In fact, Bagwell, Mavroidis, and Staiger (2004b) note that there has been no trade dispute in which a developing country (defined as a non-OECD member) has imposed retaliatory measures to induce compliance when faced with a trade violation. ${ }^{16}$

The first problem in modelling asymmetry is that if a country is truly small from a trade perspective then, under the current trading system, it will not obtain multilateral tariff reductions in products that it alone exports. This is simply due to the reciprocal nature of tariff concessions. If a small country's tariff reduction does not affect the price received by an exporter then the exporter has no incentive to offer a reciprocal tariff concession to the small country. ${ }^{17}$ Therefore we consider a case where each country trading with a large country is small individually but large collectively. We then ask if there is a problem in the current enforcement system that may be ameliorated with an alternative mechanism.

Suppose that there is a set of small countries, that are jointly large in importing a particular good, and that they all export a common good (that no other set of countries export) to a single large country. If the small countries can threaten joint retaliation they can achieve tariff concessions from the large country. However, such a threat may not be credible because no small country has an individual incentive to punish a deviation by the large country (since the terms-of-trade gain for an individual small country from raising its tariff is close to zero). We can think of the optimal joint punishment for compliance purposes as a public good subject to a free rider problem. Therefore, ex-ante the small countries may fail to extract significant tariff concessions from the large country. We now

\footnotetext{
${ }^{16}$ Further empirical evidence on this issue is available in Bown (2004a and 2004b).

${ }^{17}$ One alternative is that small countries "offer" non-trade related concessions, as was done with TRIPS in the Uruguay Round. However, here we want to focus strictly on the exchange of trade concessions.
} 
show this free rider problem continues to exist even if fines (supported by tariffs) are used to enforce cooperation but that it can be overcome by the use of bonds.

To focus the analysis on the coordination problem, the only change we make in the setup is to assume that the foreign country is now a collection of $\kappa$ independent and identical small countries. Each small country's demand and supply functions equal $D_{i}^{*} / \kappa$ and $S_{i}^{*} / \kappa$ respectively and its payoff in sector $i$ is simply $W_{i}^{*} / \kappa$ where $\kappa$ is a positive integer. It should be immediately obvious from the welfare expression in (2) that if the small countries could coordinate their efforts and maximize their joint objective, our analysis of cooperation between two symmetric countries enforced via the threat of tariff retaliation would remain relevant since the joint objective of the small countries $\Sigma_{i, \kappa} W_{i}^{* \kappa}=\left(\Sigma_{i} \kappa W_{i}^{*}\right) / \kappa$ equals $W$ under symmetry. Thus, their jointly optimal Nash tariff would still be $\tau^{N}$.

However, a problem arises if there is no instrument via which small countries can successfully coordinate their choices. In this case if individual small countries consider punishments (or deviations) the Nash tariff $\tau^{* N \kappa}$ each imposes in its import sector, $y$, is given by

$$
\frac{\tau^{* N \kappa}}{p^{w}}=\frac{1}{\kappa} \frac{1}{\varepsilon^{*}}+(\lambda-1) \frac{S^{*} / M^{*}}{\xi^{*}}
$$

where all the variables are defined similarly to $\tau^{N}$ in (4). The key difference is that the terms-of-trade effect is now reduced to a fraction $1 / \kappa$ of its previous value. Thus at the original prices implied by (4), the Nash tariff for the large country is unchanged but for the small countries it is lower than before. ${ }^{18}$

From (29) we can see that if the number of small countries $\kappa$ is sufficiently high and $\lambda=1$, the Nash tariff of each is zero. Under such circumstances, there is nothing a small country can individually offer to or credibly threaten the large country with. Thus, in the case of the standard enforcement mechanism that uses only tariffs, explored in section 3.1, the only self-enforcing tariff for the large country is to set its cooperative tariff at the Nash, $\tau^{N}$. So relative to the case where small countries act jointly, they are now clearly worse off-they face $\tau^{N}>\tau^{c \tau}$ on their exports and impose $\tau^{* N \kappa}<\tau^{* N}$ on their imports - and

\footnotetext{
${ }^{18}$ The variables in (29) refer to foreign's import sector, $y$. At the original prices we have $z_{y}^{*}=z_{x}$ for all the variables $z=S, M, \varepsilon, \xi$ because of symmetry.
} 
the large country is better off. The use of fines backed by tariff retaliation, as we explored in section 3.2, fails to improve upon this outcome for the small countries because, as we showed before, the maximum WRP fine is tied to the payoff under infinite Nash reversion in tariffs, which is $\tau^{* N \kappa}$ in the absence of coordination.

The general solution under tariff retaliation with $\lambda \geq 1$ and a finite number of small countries entails an asymmetric solution where the large country sets a cooperative tariff that is higher than the one it faces from the small countries (see the proof of Proposition 3 in the appendix). The basic motive is simply the inability of the latter to retaliate jointly. However, if bonds were posted with a third party then the global optimum (i.e. the symmetric tariff in (6)) can be reached. What is perhaps more interesting is that the inability of small countries to act jointly in setting tariffs becomes an advantage when bonds are used. To see why this is so, and more generally how bonds improve on cooperation even if each small country acts alone, we derive the bond that is required by each country to achieve the global optimum.

For the large country the payoffs under cooperation and deviation are still defined by (8) and (9) respectively but now the foreign cooperative tariffs are not necessarily the same as its own. We assume that if it deviates against any of the small countries then it deviates against all, which may be justified by the fact that all of them are identical. Thus we require the value of the bond to be such that the IC in (24) is satisfied with equality when the cooperative tariffs equal $\tau^{g}$. Solving this we obtain

$$
b^{\kappa}=W^{D}\left(\tau^{N}, \tau^{* c \kappa}=\tau^{g}\right)-W^{C}\left(\tau^{g}\right)
$$

The required bond is simply the terms-of-trade gain for the large country from deviating against the small countries when all tariffs are at the global optimum. ${ }^{19}$

\footnotetext{
${ }^{19}$ If this country deviated then it would forfeit the bond, which would be divided according to the market share of exporters, in this case each would receive $b^{\kappa} / \kappa$. Since we do not model equilibrium deviations in this section this division does not affect the results.
} 
For each of the individual small countries, the required bond solves the following IC

$$
W^{* D}\left(\tau^{* N \kappa}, \tau^{g}\right) / \kappa-b^{* \kappa}+\frac{\delta}{1-\delta} W^{* C}\left(\tau^{g}\right) / \kappa=\frac{W^{* C}\left(\tau^{g}\right) / \kappa}{1-\delta}
$$

which yields

$$
b^{* \kappa}=\left[W^{* D}\left(\tau^{* N \kappa}, \tau^{g}\right)-W^{* C}\left(\tau^{g}\right)\right] / \kappa
$$

Thus the total value of the bonds posted by the $\kappa$ identical small countries is $W^{* D}\left(\tau^{* N \kappa}, \tau^{g}\right)-$ $W^{* C}\left(\tau^{g}\right)$, which is lower than the bond posted by large. The reason is simple. The value of each bond is equal to the gain from individual deviation. This is lower for the small countries because their deviation entails a tariff $\tau^{* N \kappa}<\tau^{N}$. Thus bonds not only solve the coordination problem but they turn the small country disadvantage into an advantage: the need to post a relatively lower bond. This would be valuable if we modelled an opportunity cost of posting bonds and/or motives for equilibrium deviations. ${ }^{20}$

We summarize the discussion above in the following proposition.

Proposition 3 (Enforcement under tariffs versus bonds with asymmetric countries):

In a trade agreement between a large country and a group of $\kappa$ uncoordinated small countries, the most cooperative tariff set by the large country, $\tau^{c \kappa}$, is

(a) higher than the global optimum, $\tau^{g}$, and the tariff set by each of the small countries, $\tau^{* c \kappa}$ if the agreement is enforced only by tariffs

(b) equal to $\tau^{* c \kappa}$ and both are equal to $\tau^{g}$ if the agreement is enforced by bonds held by a third party.

Moreover, the bond posted by the large country, $b^{\kappa}$, exceeds the total value of the bonds posted by the small countries, $\kappa b^{* \kappa}$.

\footnotetext{
${ }^{20}$ The gains from trade are maximized when the global optimum is implemented. But one may wonder why in the complete absence of coordination between small countries the large country would not try to use its bargaining power. By solving the enforcement problem, the existence of bonds may also allow the small countries to coordinate at the time of the negotiation, making the symmetric solution plausible. If such coordination fails to occur then the outcome predicted by the model is still the global optimum as long as transfers were available. But the distribution of surplus between the large and small countries would then depend on the specifics of the bargaining model.
} 


\subsection{Compensation under alternative mechanisms}

As we note in the Introduction, WTO dispute settlement remedies have both an enforcement and a compensation role. Thus far we have focused only on the enforcement aspect and shown that enforcement cannot generally be improved by replacing the current system with fines (or bonds unless these are held by a third party). Since the most cooperative tariff under those alternative mechanisms is identical so is the payoff to governments. The reason is that our model assumes perfect foresight and no shocks, so that no violations occur in equilibrium. Clearly the assumption of no shocks is not realistic and consequently neither is the result that no deviations occur along the equilibrium path. We observe plenty of WTO disputes and violations are found to have occurred in many of the cases. This is important because once we allow for deviations to occur in equilibrium, the payoffs to countries depend not only on the cooperative tariff but also on the exact mechanism used to deal with violations. We now show that fines can generate higher compensation for the injured country at the same cost to the violator even if the cooperative tariff enforced is identical.

We illustrate our point in the simplest possible way. We assume governments base their policies on the set of parameters currently observed and expect them to hold in the future. We then consider the impact of an unexpected shock, e.g. a shock to the political economy parameter $\lambda$ in (2) so that in a given period a country desires a higher tariff than the cooperative level previously set. In the following period $\lambda$ returns to the original level. Such a shock and the resulting tariff increase would likely trigger a dispute and a ruling against the country because tariffs are bound in the WTO and are not on a contingent set of parameters (probably because it is difficult to write an agreement that is conditional on parameters that may be hard to observe by other countries). ${ }^{21}$

The question we ask is the following: Given that a country deviates from the agreement due to an unexpected shock, under which mechanisms are the continuation payoffs higher?

\footnotetext{
${ }^{21}$ An alternative way to model this is to assume that the governments anticipate that shocks will occur and have a well defined distribution of all possible shocks. Bagwell and Staiger (2005) analyze this issue when governments have private information about future political shocks. One of their findings is that a transfer can help in the implementation of efficient tariffs.
} 
We focus on fines supported by either tariffs or bonds not held by third parties so that either yields the same enforcement outcome as temporary tariff retaliation. Since we focus on the most cooperative tariff, the minimum payoff that the deviating country can be held to under either alternative is the discounted Nash payoff, $W^{N} \delta /(1-\delta)$. The question then is which alternative yields a higher compensation for the injured country. The continuation payoff for the injured country under temporary tariff retaliation when the most cooperative WRP is implemented is

$$
V^{* \tau} \equiv \delta W^{* P} \frac{1-\delta^{n^{\max }}}{1-\delta}+\frac{\delta^{n^{\max }+1}}{1-\delta} W^{* C}
$$

where we recall that the payoff for the injured country under the punishment phase $W^{* P}$ exceeds $W^{* C}$ because the punishment involves the injured setting its optimal tariff $\tau^{*}=\tau^{N}$ and the other country setting its cooperative tariff, $\tau^{c}$.

Under a fine supported by infinite Nash tariff reversion the payoff analogous to (33) is

$$
V^{* f} \equiv \delta f^{\max }+\frac{\delta}{1-\delta} W^{* C}
$$

This payoff reflects the received fine and the immediate resumption of cooperation with a payoff $W^{* C}$ per period, identical to the one in (33) since we derived that both sustain the same cooperative tariff. Therefore the compensation under fines is higher than under tariff retaliation if and only if the expression in (34) exceeds (33). This yields the following condition for the fine:

$$
f^{\max }>\frac{1-\delta^{n^{\max }}}{1-\delta}\left(W^{* P}-W^{* C}\right)
$$

With this condition we are ready to compare the compensation properties of each mechanism and rank them. Since we consider unanticipated shocks we think that a reasonable ranking of the two can be established by comparing their payoffs under cooperation and their continuation payoffs if a shock does occur. Thus we use the following definition. A trade agreement enforced by fines generates a Pareto improvement relative to one using tariffs if the following inequalities hold: (i) $W^{C}\left(\tau^{c f}\right) \geq W^{C}\left(\tau^{c \tau}\right)$; (ii) $W^{* C}\left(\tau^{c f}\right) \geq W^{* C}\left(\tau^{c \tau}\right)$; 
(iii) $V^{f} \geq V^{\tau}$; and (iv) $V^{* f} \geq V^{* \tau}$ with at least one holding strictly. We can now state the following.

Proposition 4 (Compensation properties and ranking of tariffs versus fines):

In the presence of unanticipated shocks, e.g. to $\lambda$, a trade agreement between two symmetric countries that is enforced by WRP fines supported by tariffs

(a) yields higher compensation for the injured country $\left(V^{* f}>V^{* \tau}\right)$ and

(b) generate a Pareto improvement

relative to a similar agreement enforced by tariff retaliation alone.

The first part of the proposition says that the continuation payoff for the injured country after a shock is higher under fines, i.e. the inequality in (35) always holds. We show this in the appendix, below we will provide the intuition. The second part is a corollary of part (a) and of proposition 1. In proposition 1 we show that fines and tariffs enforce the same cooperative tariff so $W^{C}\left(\tau^{c f}\right)=W^{C}\left(\tau^{c \tau}\right)$ and similarly for foreign due to symmetry. Moreover, we also showed that the WRP continuation payoff that a country is held to in equilibrium is the same under the two alternatives, $V^{f}=V^{\tau}$. So fines generate a Pareto improvement.

To see why inequality (35) always holds, note that when the IC under fines binds then $f^{\max }$ is given by (19), which due to symmetry is also equal $\left(W^{* C}-W^{* N}\right) /(1-\delta)$. Using this and the definition of the payoffs we can rewrite (35) as

$$
\frac{W^{* C}-W^{* N}}{1-\delta}>\frac{1-\delta^{n^{\max }}}{1-\delta}\left(W_{y}^{*}\left(\tau^{*}=\tau^{N}\right)-W_{y}^{*}\left(\tau^{*}=\tau^{c}\right)\right)
$$

The value of the fine received by the injured country (i.e. the left hand side) is equal to the present discounted value of cooperation in the trade agreement relative to infinite Nash reversion. This value needs to exceed any temporary gains that the injured country can obtain by raising its tariff during the punishment phase of $n^{\max }$ periods. The latter gain is simply the terms-of-trade benefit that it obtains from using its Nash tariff relative to the cooperative one. By using the definition for $n^{\max }$ in (13) and simplifying we can show 
this condition always holds. The underlying reason is that tariffs can transfer income by changing terms-of-trade but relative to a fine they do so inefficiently because tariffs cause a deadweight loss in the process.

\section{Conclusion}

There is a widespread opinion that the WTO's dispute settlement system needs improvement. In particular, there is much concern about the use of tariff retaliation as the sole mechanism for dealing with member countries that fail to comply with a WTO ruling against them. In this paper, we analyze alternative mechanisms based on financial compensation and argue that one of their major problems is enforcement.

Ultimately, the enforcement of monetary fines may require the use of some type of retaliatory instrument and if such is the case, fines fail to yield anymore cooperation than tariffs. We also analyze whether bonds (posted prior to trading and revoked in case of a violation) can substitute for tariffs. Here, the key issue is whether they can be posted with a third party or not. If access to a third party is missing, bonds also fail to improve upon tariffs. Thus, despite their problems, a desirable aspect of retaliatory tariffs is that they are controlled by injured parties and can be used in the event a violating country fails to comply with the ruling of a WTO panel.

The major problem with tariff retaliation as a means of settling disputes is that tariffs can only be used by countries that have sufficient market power in world markets. As a result, the WTO's current dispute settlement system does not provide its smaller and/or developing country members with any real ability to retaliate against violations by other countries. As Bagwell, Mavroidis, and Staiger (2004a) have shown, making the right to retaliate tradable via an auction can help remedy this defect. A similar argument applies to the use of fines. If fines are indeed adopted, they would need to be tradable for small countries to benefit from their introduction. This would either require the posting of bonds with third parties or the existence of large countries willing to bid for the right to collect a fine. 
We also showed that fines have an advantage over tariff retaliation as a primary remedy: if a violation does occur, the payoff to an injured country is higher under fines even though the cost of the penalty for a violating country is unchanged. The intuition is simple: tariffs are an inefficient form of compensation because the welfare gain they generate for an injured country (if it has market power) is always less than the welfare cost on the country facing the tariff punishment. This establishes the ex-post efficiency of fines.

Future research should build on these insights to determine whether the WTO's dispute system should move to financial compensation as the primary remedy. We see two important aspects to be modelled, both of which related to the ex-ante efficiency of tariffs as an enforcement mechanism. The first is to allow injured countries to select the goods on which they retaliate, as observed in recent cases where retaliating parties selected products produced in swing states. By targeting states with greater political influence, tariffs may be more effective in generating pressure through exporters for the violating government to comply with the WTO's ruling. As Lawrence (2003) notes, parties often retaliate in a fashion that maximizes incentives for compliance. This advantage of tariffs relative to fines can be reinforced when fines are raised via general taxation. In this case the punishment for violating the trade agreement, the fine, is dispersed and can go unnoticed. Therefore future research should extend our analysis to incorporate this ex-ante efficiency of tariffs relative to fines and provide a more definite ranking of the two. 


\section{Appendix}

\subsection{Analytical expressions}

The Nash tariffs in (4) are obtained by solving the following first-order condition for $\tau$

$$
W_{\tau}=0:\left(1+p_{\tau}^{w}\right)\left[\tau M_{p}+(\lambda-1) S\right]-p_{\tau}^{w} M=0
$$

In (4) $1 / \varepsilon \equiv \frac{M^{*}}{p^{w} M_{p}^{*}}$ and $\xi \equiv-\frac{\partial M}{\partial p^{w}} \frac{p^{w}}{M}=-M_{p} p^{w} / M$.

The global optimum tariffs in (6) are obtained by solving the following first-order condition for $\tau^{c}$

$$
W_{x}\left(\tau^{c}\right)+W_{y}\left(\tau_{y}^{*}=\tau^{c}\right)=0:\left(1+p_{\tau}^{w}\right)\left[\tau^{c} M_{p}+(\lambda-1) S\right]=0
$$

The Nash tariff for each small country in (29) is obtained by solving the following first-order condition for $\tau^{* \kappa}$, where all variables correspond to their import good, $y$.

$$
\begin{aligned}
W_{\tau^{* \kappa}}^{\kappa} & =0:\left(1+p_{\tau^{* \kappa}}^{w}\right)\left[\tau^{* \kappa} M_{p}^{* \kappa}+(\lambda-1) S^{* \kappa}\right]-p_{\tau^{* \kappa}}^{w} M^{* \kappa}=0 \\
\tau^{\kappa} & =\frac{p_{\tau^{* \kappa}}^{w}}{1+p_{\tau^{* \kappa}}^{w}} \frac{M^{*}}{M_{p}^{*}}-(\lambda-1) \frac{S^{*}}{M_{p}^{*}}
\end{aligned}
$$

where in the second line we use the property that the demand and supply for each $\kappa$ are identical to the original value divided by $\kappa$ s.t. $z^{\kappa}=z / \kappa$ for $z=S^{*}, M^{*}, M_{p}^{*}$. We then implicitly differentiate the market clearing condition for $y$ to obtain $p_{\tau^{* \kappa}}^{w}$

$$
M\left(p^{w}\right)+(\kappa-1) M^{* \kappa}\left(p^{w}+\tau^{j \neq \kappa}\right)+M^{* \kappa}\left(p^{w}+\tau^{\kappa}\right)=0
$$

We obtain $p_{\tau^{* \kappa}}^{w} /\left(1+p_{\tau^{* \kappa}}^{w}\right)=\frac{1}{\kappa}\left(-M_{p}^{*} / M^{\prime}\left(p^{w}\right)\right)$. Employing the same definitions as before, $1 / \varepsilon^{*} \equiv \frac{M}{p^{w} M_{p}}$ and $\xi^{*} \equiv-\frac{\partial M^{*}}{\partial p^{w}} \frac{p^{w}}{M^{*}}=-M_{p}^{*} p^{w} / M^{*}$, we have (29). 


\subsection{Additional Proofs}

\section{Proposition 3}

(a) Since the large country has $\kappa$ identical ICs, assume that if it deviates in one of them, it deviates in all. The payoffs are defined as in section 3.1 but now the foreign tariffs are not symmetric, $\tau^{* c \kappa}$ is to be determined and $\tau^{* N \kappa}$ is given in (29). Thus the IC for the large country is

$$
W^{D \kappa}+\frac{\delta}{1-\delta} W^{N \kappa} \leq \frac{W^{C \kappa}}{1-\delta}
$$

which is the same as

$$
W_{x}\left(\tau^{N}\right)+W_{y}\left(\tau^{* \kappa \kappa}\right)+\frac{\delta}{1-\delta}\left(W_{x}\left(\tau^{N}\right)+W_{y}\left(\tau^{* N \kappa}\right)\right) \leq \frac{W_{x}\left(\tau^{c \kappa}\right)+W_{y}\left(\tau^{* c \kappa}\right)}{1-\delta}
$$

For each of the small countries $W^{* \kappa}=W^{*} / \kappa$ so we can multiply both sides of their IC by $\kappa$ to rewrite them as follows:

$$
W_{y}^{*}\left(\tau^{* N \kappa}\right)+W_{x}^{*}\left(\tau^{c \kappa}\right)+\frac{\delta}{1-\delta}\left(W_{x}^{*}\left(\tau^{N}\right)+W_{y}^{*}\left(\tau^{* N \kappa}\right)\right) \leq \frac{W_{x}^{*}\left(\tau^{c \kappa}\right)+W_{y}^{*}\left(\tau^{* c \kappa}\right)}{1-\delta}
$$

We prove $\tau^{c \kappa}>\tau^{* c \kappa} \geq \tau^{g}$ by contradiction. Assume that the lowest self-enforcing cooperative tariff is $\tau^{c \kappa}=\tau^{* c \kappa} \geq \tau^{g}$ and that it is such that the IC in (39) binds. We then show that when $\tau^{c \kappa}=\tau^{* c \kappa}$ the IC in (38) is violated. Since the RHS of (38) and (39) are equal at $\tau^{c \kappa}=\tau^{* \kappa \kappa}$ (due to symmetry) we need only show that the LHS of (38) exceeds that of $(39)$ :

$$
\begin{aligned}
W_{x}\left(\tau^{N}\right)+W_{y}\left(\tau^{* \kappa \kappa}\right)+\frac{\delta}{1-\delta}\left(W_{x}\left(\tau^{N}\right)+W_{y}\left(\tau^{* N \kappa}\right)\right) & \\
& >W_{y}^{*}\left(\tau^{* N \kappa}\right)+W_{x}^{*}\left(\tau^{c \kappa}\right)+\frac{\delta}{1-\delta}\left(W_{x}^{*}\left(\tau^{N}\right)+W_{y}^{*}\left(\tau^{* N \kappa}\right)\right)
\end{aligned}
$$

which is the same as

$$
W_{x}\left(\tau=\tau^{N}\right)-W_{x}\left(\tau=\tau^{* N \kappa}\right)>\delta\left(W_{y}\left(\tau^{*}=\tau^{N}\right)-W_{y}\left(\tau^{*}=\tau^{* N \kappa}\right)\right)
$$


where we use the symmetry, $W_{x}^{*}=W_{y}, W_{y}^{*}=W_{x}$. The inequality in (40) always holds because

(i) $W_{x}\left(\tau^{N}\right)-W_{x}\left(\tau^{* N \kappa}\right)>0$ since $\tau^{N}$ is the optimal value for $W_{x}$

(ii) $W_{y}\left(\tau^{*}=\tau^{N}\right)-W_{y}\left(\tau^{*}=\tau^{* N \kappa}\right)<0$ since $\tau^{N}=\tau^{* N}>\tau^{* N \kappa}$ and $d W_{y}\left(\tau^{N}\right) / d \tau^{*}<0$ (recall that $y$ is the export for home)

If $\tau^{c \kappa}$ alone is increased then eventually (38) would hold. However, an increase in $\tau^{c \kappa}$ alone causes (39) to be violated since it reduces the gains from cooperation (the RHS of (39)) by a greater amount than the gains from deviation (the LHS). Thus both tariffs must be raised but $\tau^{c \kappa}$ more so than $\tau^{* c \kappa}$. To see why, suppose both tariffs were increased by the same amount up to a point where (38) binds. Then, once again, we would have a situation where, at identical tariffs, the LHS of (38) exceeds that of (39). The difference is that now since (38) just binds and because at a symmetric tariff the RHS of both IC are identical, there must be slack in (39). This implies that a $\tau^{* \kappa}<\tau^{c \kappa}$ is self-enforcing since the reduction in $\tau^{* c \kappa}$ reduces the slack in (39) without violating (38). A related argument can be constructed even if (38) does not bind in a symmetric equilibrium: starting from the same point, equal increases in the two tariffs (i.e. $\tau^{* \kappa \kappa}$ and $\tau^{c \kappa}$ ) have similar marginal effects on the gains from deviation and cooperation in (38) and (39) but since we require a larger increase in slack in (38), the increase in $\tau^{c \kappa}$ needs to be larger.

(b) If the large country posts a bond $b^{\kappa}$ and each of the small countries post a bond $b^{* \kappa}$ with a third party, as described in section 3.4, they can enforce $\tau^{g}$, the global optimum. To determine the minimum values of these bonds we need to solve the respective IC when the cooperative tariffs are $\tau^{g}$. For $b^{* \kappa}$ this is already given in (31). We obtain $b^{\kappa}$ in (30) by solving

$$
W^{D}\left(\tau^{N}, \tau^{g}\right)-b^{\kappa}+\frac{\delta}{1-\delta} W^{C}\left(\tau^{g}\right)=\frac{W^{C}\left(\tau^{g}\right)}{1-\delta}
$$


Value of bonds: We show that $b^{\kappa}>\kappa b^{* \kappa}$ by proving the following inequality

$$
\begin{aligned}
b^{\kappa} & =W^{D}\left(\tau^{N}, \tau^{* c \kappa}=\tau^{g}\right)-W^{C}\left(\tau^{g}\right) \\
& >W^{* D}\left(\tau^{* N \kappa}, \tau^{g}\right)-W^{* C}\left(\tau^{g}\right) \\
& =\kappa b^{* \kappa}
\end{aligned}
$$

First, $W^{D}\left(\tau^{N}, \tau^{* c \kappa}=\tau^{g}\right)-W^{C}\left(\tau^{g}\right)=W_{x}\left(\tau^{N}\right)-W_{x}\left(\tau^{g}\right)$. Similarly, $W^{* D}\left(\tau^{* N \kappa}, \tau^{g}\right)-$ $W^{* C}\left(\tau^{g}\right)=W_{y}^{*}\left(\tau^{* N \kappa}\right)-W_{y}^{*}\left(\tau^{g}\right)=W_{x}\left(\tau=\tau^{* N \kappa}\right)-W_{x}\left(\tau^{g}\right)$, where the last equality is due to symmetry. Therefore $b^{\kappa}-\kappa b^{* \kappa}=W_{x}\left(\tau^{N}\right)-W_{x}\left(\tau=\tau^{* N \kappa}\right)$, which is positive because $\tau^{N}$ maximizes $W_{x}$ and $\tau^{* N \kappa}<\tau^{N}$. $\square$

\section{Proposition 4:}

(a) $V^{* f}>V^{* \tau}$. These payoffs are defined in (34) and (33). Using these and simplifying we obtain the condition in (35) in the text. We now show it must hold.

$$
\begin{aligned}
f^{\max } & >\frac{1-\delta^{n^{\max }}}{1-\delta}\left(W^{* P}-W^{* C}\right) \\
& \Leftrightarrow f^{\max }>\frac{1-\delta^{\max ^{\max }}}{1-\delta}\left(W_{y}^{*}\left(\tau^{*}=\tau^{N}\right)-W_{y}^{*}\left(\tau^{*}=\tau^{c}\right)\right) \\
& \Leftrightarrow \frac{W^{C}-W^{N}}{1-\delta}>\frac{1-\delta^{n^{\max }}}{1-\delta}\left(W_{x}\left(\tau^{N}\right)-W_{x}\left(\tau^{c}\right)\right) \\
& \left.\Leftrightarrow W^{C}-W^{N}>\left(1-\delta^{n^{\max }}\right)\left(W_{x}\left(\tau^{N}\right)-W_{x}\left(\tau^{c}\right)\right)\right) \\
& \Leftrightarrow W^{C}-W^{P}>\left(W_{x}\left(\tau^{N}\right)-W_{x}\left(\tau^{c}\right)\right) \\
& \Leftrightarrow W_{y}\left(\tau^{* C}\right)-W_{y}\left(\tau^{* N}\right)>\left(W_{x}\left(\tau^{N}\right)-W_{x}\left(\tau^{c}\right)\right) \\
& \Leftrightarrow W^{C}>W^{N}
\end{aligned}
$$

where the second line uses the definition of the punishment and cooperative payoffs, the third the definition of $f^{\max }$ in (19) and the symmetry assumption across countries. The fourth line uses the definition of deviation and cooperative payoffs. The fifth line uses the definition of $\delta^{n^{\max }}$ in (13) and simplifies. The sixth uses the definitions of the payoffs. The last line is necessarily true because Nash tariffs are inefficient and each country's payoff 
under own and foreign Nash tariffs is lower than its cooperative payoff.

(b) Our definition of Pareto improvement in the text is satisfied if (i) $W^{C}\left(\tau^{c f}\right)=$ $W^{C}\left(\tau^{c \tau}\right)$; (ii) $W^{* C}\left(\tau^{c f}\right)=W^{* C}\left(\tau^{c \tau}\right)$; (iii) $V^{f}=V^{\tau}$; and (iv) $V^{* f}>V^{* \tau}$. Since the last inequality is shown in part (a) we need only show the first three equalities. From proposition 1 we know that $\tau^{c f}=\tau^{c \tau}$. Therefore $W^{C}\left(\tau^{c f}\right)=W^{C}\left(\tau^{c \tau}\right)$. Given symmetry we also have $W^{* C}\left(\tau^{c f}\right)=W^{* C}\left(\tau^{c \tau}\right)$. As we show in section 3.1, equation (13), $V^{\tau}=V^{\tau \min }=\frac{\delta}{1-\delta} W^{N}$. In section 3.2, equation (18) shows that $V^{f}$ is also equal to that value. Thus, under the most cooperative tariff we have $V^{\tau}=V^{f}$. 


\section{References}

[1] Bagwell, K. and R. Staiger. 1990. "A Theory of Managed Trade." American Economic Review, 80, 779-795.

[2] —. 1999. "An Economic Theory of GATT." American Economic Review, 89(1), 215248.

[3] —. 2005. "Enforcement, Private Political Pressure, and the GATT/WTO Escape Clause." Journal of Legal Studies, 34(2), 471-513.

[4] Bagwell, K., Mavroidis, P. and R. Staiger. 2004a. "The Case for Auctioning Countermeasures in the WTO." Mimeo, Columbia University.

[5] Bagwell, K., Mavroidis, P. and R. Staiger. 2004b. "The Case for Tradable Remedies in WTO Dispute Settlement." Mimeo, Columbia University.

[6] Bown, C. 2004a. "On the Economic Success of GATT/WTO Dispute Settlement." Review of Economics and Statistics, 86(3), 811-823.

[7] Bown, C. 2004b. "Developing Countries as Plaintiffs and Defendants in GATT/WTO Trade Disputes." World Economy, 27, 59-80.

[8] Bronckers, M., Van Den Broek, N. 2005. "Financial Compensation in the WTO: Improving the Remedies of WTO Dispute Settlement." Journal of International Economic Law, 8, 101-126.

[9] Dixit, A. 1987. "Strategic Aspects of Trade Policy," in Advances in Economic Theory, T. Bewley (ed.), Cambridge University Press, 329-62.

[10] Ethier, W. J., 2003. "Intellectual Property Rights and Dispute Settlement in the World Trade Organization." Mimeo.

[11] Farrell, J. and E. Maskin. 1989. "Renegotiation in Repeated Games." Games-andEconomic-Behavior, 1(4), 327-60.

[12] Hoekman, B. M., and M. M. Kostecki. 2001. The Political Economy of the World Trading System. Oxford University Press, New York, NY.

[13] Hoekman, B. and K. Saggi. 2006. "Tariff Bindings and Bilateral Cooperation on Export Cartels." Journal of Development Economics, forthcoming. 
[14] Hudec, R. 2002. "The Adequacy of WTO Dispute Settlement Remedies: A Developing Country Perspective," in Aaditya Mattoo, Bernard Hoekman, and Philip English, eds., Development, Trade, and the WTO: A Handbook, The World Bank, Washington, D.C.

[15] Lawrence, R. 2003. Crimes and Punishments? Retaliation under the WTO. Institute of International Economics, Washington, D.C.

[16] Limão, Nuno. 2005. "Trade Policy, Cross-border Externalities and Lobbies: Do Linked Agreements Enforce More Cooperative Outcomes?" Journal of International Economics, 67(1), 175-199.

[17] Grossman, G. and E. Helpman. 1994. "Protection for Sale." American Economic Review, 84(4), 833-50.

[18] Shaffer, G. 2003. "How to Make the WTO Dispute Settlement System Work for Developing Countries: Some Proactive Developing Country Strategies." International Centre for Trade and Sustainable Development, Working Paper No. 5.

[19] Van Damme, E. 1989. "Renegotiation-proof equilibria in repeated Prisoners' Dilemma." Journal of Economic Theory, 47, 206-217. 